\title{
Trends and Disparities in Functional Impairment among US Adults Age 55-64, 2002 to 2016
}

J Gen Intern Med 36(12):3903-6 DOI: $10.1007 / \mathrm{s} 11606-020-06209-y$

(c) Society of General Internal Medicine 2020

\section{INTRODUCTION}

Over the past decade, US midlife morbidity and mortality have increased, contributing to declines in life expectancy. ${ }^{1}$ This worsening health status has been experienced disproportionately by low-socioeconomic status (SES) and racial/ethnic minority individuals ${ }^{2,3}$ and is associated with functional deterioration among low-SES middle-aged adults. ${ }^{4}$ Yet it is unclear if disparities in functional status are rising. Functional impairment may not be recognized as a health problem for middle-aged adults, but it is common and, as for older adults, associated with disability and death. ${ }^{5}$ Our objective was to examine functional trends among US midlife adults to determine whether and how changes in disparities are concentrated among particular demographic groups.

\section{METHODS}

We used the Health and Retirement Study (HRS) to identify a nationally representative sample of community-dwelling adults age 55-64 surveyed during 2002-2016 ( $N=48,340$ person-years; 17,516 respondents). We focused on this age group just prior to Medicare eligibility at age 65 , as midlife functional changes could magnify health care costs. Functional impairment was defined as any difficulty due to health/ memory problems with activities of daily living (ADLs: walking, dressing, bathing, eating, transferring, and toileting) or any difficulty with instrumental ADLs (IADLs: preparing meals, grocery shopping, using the telephone, taking medication, and managing finances).

\section{Prior Presentations: None}

Received August 21, 2020

Accepted August 31, 2020

Published online September 11, 2020
Though HRS collects data longitudinally, we used a serial cross-sectional design to estimate changes in prevalence of ADL and IADL limitations overall and within sociodemographic groups, using survey weights for yearly populationbased estimates. We tested for trend differences between groups using Rao-Scott $\chi^{2}$ and logistic regression. All analyses were conducted with Stata version 15 (StataCorp). The University of Michigan institutional review board approved the study.

\section{RESULTS}

There were small but significant differences in the prevalence of ADL $(P=0.019)$ and IADL $(P=0.002)$ limitations among adults age 55-64 over time. The prevalence of both ADL and IADL limitations increased by 1.2 percentage points (pp) from 2002 to 2016 (Table 1 ).

Most changes in functional impairment prevalence within gender, race/ethnicity, and urbanicity groups were small and non-significant (Table 1). However, those with lower education experienced greater worsening in functional impairment $(+3.3 \mathrm{pp}$ increase in $\mathrm{ADL}[P=0.003]$, $+2.3 \mathrm{pp}$ increase in IADL $[P=0.026]$ limitations), as did those with lower incomes $(+4.6 \mathrm{pp}$ increase in ADL $[P=0.009],+3.0 \mathrm{pp}$. increase in IADL limitations $[P=$ $0.062]$ ). While there were prominent functional disparities by SES, these gaps did not grow over time (Fig. 1). Compared with higher-education individuals, lowereducation individuals had $9.4 \mathrm{pp}$ higher ADL $(P<0.001)$ and $6.8 \mathrm{pp}$ higher IADL impairments $(P<0.001)$ (Fig. 1c and d) in 2016; lower-income individuals had $20.0 \mathrm{pp}$ higher ADL $(P<0.001)$ and $17.7 \mathrm{pp}$ higher IADL impairments $(P<0.001)$ (Fig. 1e and f). Relative to non-Hispanic Whites, non-Hispanic Blacks experienced greater functional impairments (11.6 pp higher ADL $[P<0.001]$ and $9.1 \mathrm{pp}$ higher IADL limitations $[P<0.001])$, as did Hispanics $(10.5$ pp higher ADL $[P<0.001]$ and $5.4 \mathrm{pp}$ higher IADL limitations $[P=$ 0.018]) (Fig. 1a and b). 
Table 1 Change in Prevalence of Limitations in Activities of Daily Living and Instrumental Activities of Daily Living, 2002-2016 ( $N=17,516)$

\begin{tabular}{|c|c|c|c|c|}
\hline \multirow[b]{2}{*}{ Characteristic } & \multicolumn{2}{|c|}{ Prevalence of ADL limitation* } & \multicolumn{2}{|c|}{ Prevalence of IADL limitation* } \\
\hline & $\begin{array}{l}\text { Percentage point change }{ }^{\dagger}, \\
2016 \text { vs. } 2002(\% \text { in } 2016)\end{array}$ & $P$ value ${ }^{*}$ & $\begin{array}{l}\text { Percentage point change }{ }^{\dagger}, \\
2016 \text { vs. } 2002(\% \text { in } 2016)\end{array}$ & $P$ value \\
\hline Overall & $+1.2(12.9)$ & 0.093 & $+1.2(10.1)$ & 0.100 \\
\hline \multicolumn{5}{|l|}{ Sex } \\
\hline Male & $+2.3(12.2)$ & 0.011 & $+0.7(8.7)$ & 0.39 \\
\hline Female & $+0.3(13.6)$ & 0.78 & $+1.6(11.3)$ & 0.127 \\
\hline \multicolumn{5}{|l|}{ Race/ethnicity } \\
\hline Non-Hispanic White & $+0.3(10.2)$ & 0.73 & $+0.5(8.2)$ & 0.53 \\
\hline Non-Hispanic Black & $+0.6(21.8)$ & 0.80 & $+2.2(17.3)$ & 0.32 \\
\hline Hispanic & $+3.3(20.7)$ & 0.29 & $+0.6(13.6)$ & 0.83 \\
\hline Other & $-1.9(15.9)$ & 0.69 & $+1.5(13.0)$ & 0.76 \\
\hline \multicolumn{5}{|l|}{ Educational attainment } \\
\hline High school or lower & $+3.3(18.8)$ & 0.003 & $+2.3(14.3)$ & 0.026 \\
\hline Greater than high school & $+1.8(9.4)$ & 0.030 & $+2.0(7.5)$ & 0.010 \\
\hline \multicolumn{5}{|l|}{ Income, federal poverty level } \\
\hline$\leq 250 \%$ & $+4.6(27.1)$ & 0.009 & $+3.0(22.6)$ & 0.062 \\
\hline$>250 \%$ & $-0.8(7.0)$ & 0.30 & $-0.2(4.8)$ & 0.76 \\
\hline \multicolumn{5}{|l|}{ Urbanicity ${ }^{\S}$} \\
\hline Urban & $+1.2(11.3)$ & 0.16 & $+1.3(8.6)$ & 0.18 \\
\hline Suburban & $+0.5(13.4)$ & 0.79 & $+1.2(10.5)$ & 0.42 \\
\hline Exurban & $+2.4(15.6)$ & 0.14 & $+2.0(13.0)$ & 0.24 \\
\hline
\end{tabular}

ADL activity of daily living, IADL instrumental activity of daily living

* Respondents were classified as having an ADL or IADL limitation if they reported any difficulty with or did not or could not perform a corresponding activity

†Percentage point change estimated from logistic regression incorporating complex survey weights

$\downarrow P$ values estimated by comparing predictive margins for 2016 and 2002 within subgroups after complex survey-weighted logistic regression

$\S$ Urbanicity defined by the U.S. Department of Agriculture Beale Rural-Urban Continuum codes, where urban corresponds to metropolitan counties with $\geq 1$ million population, suburban corresponds to counties in metro areas of 250,000 to 1 million, and exurban corresponds to counties in metro areas with $<250,000$ and non-metro counties with $<20,000$, including rural counties

\section{DISCUSSION}

We found that the marked increase in mortality among middle-aged adults has not been accompanied by functional deterioration of similar magnitude. However, striking midlife functional disparities among racial minority and low-SES adults have persisted. For example, compared with non-Hispanic middle-aged Whites, nonHispanic Blacks experienced nearly twice the rates of ADL and IADL impairments, and similar disparities were observed by education and income. While previous literature suggested functional status has been improving among older adults, ${ }^{6}$ this analysis adds to evidence that disability is increasing in midlife ${ }^{4}$ and highlights large persistent disparities in functional impairments based on race/ethnicity, income, and education.
Potential study limitations include (1) recall or response survey biases, (2) using self-reported outcomes, though these are the optimal approach to assessing health-related measures, and (3) HRS cohort effects, though our study focused on trends in prevalence, which should account for changing cohorts over time.

Despite these limitations, our findings have important implications for the health care of middle-aged adults in the decade prior to Medicare eligibility. It is critical for health care practitioners to identify functional impairments to mitigate the likelihood that such impairments develop or become permanent, both to improve quality of life and to reduce costs. To reduce health disparities, future work should examine the health, health care, and social drivers of functional impairment in middle-aged adults. 
a Activities of Daily Living Limitation Prevalence, by Race

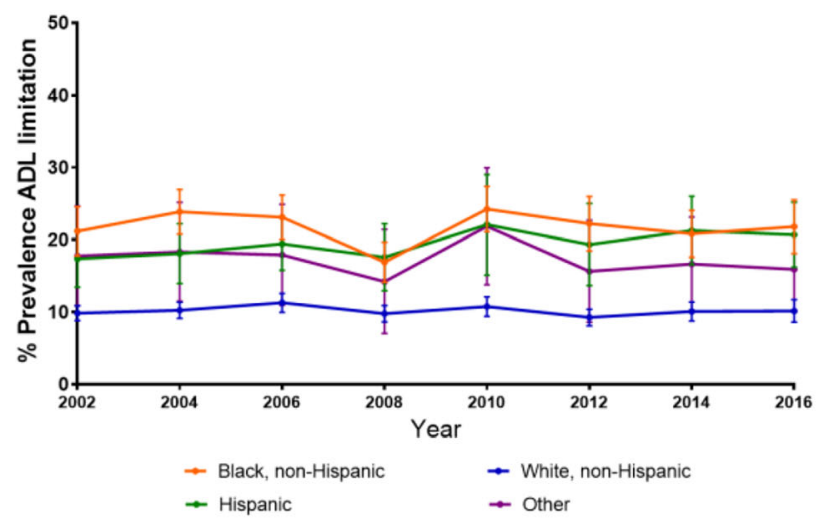

C Activities of Daily Living Limitation Prevalence, by Education

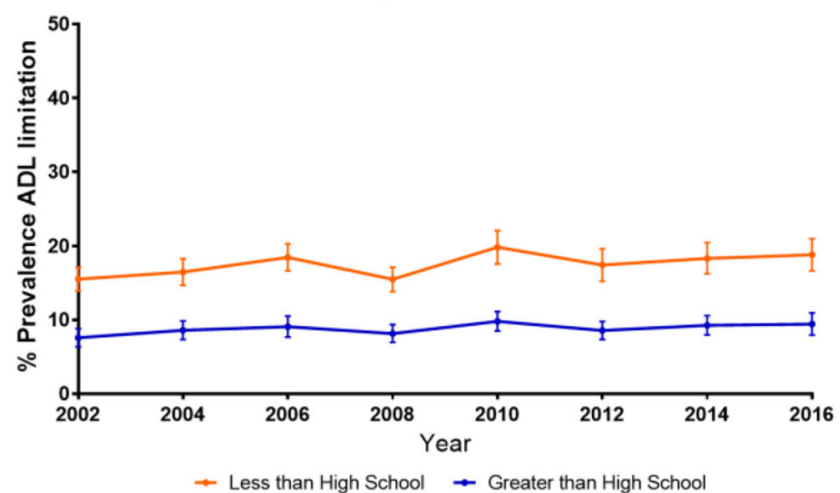

e Activities of Daily Living Limitation Prevalence, by Income

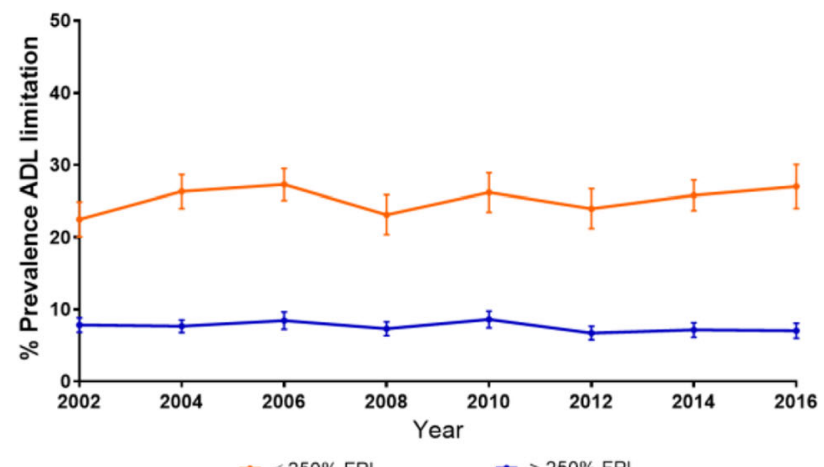

Figure 1 Trends in prevalence of activities of daily living (ADL) and instrumental activities of daily living (IADL) limitations by race and socioeconomic status, 2002-2016. Prevalence of ADL and IADL limitations by race/ethnicity (a, b), level of education (c, d), and income as a percentage of the federal poverty level (FPL) (e, f). Rao-Scott adjusted $\chi^{2}$ was used to test if the prevalence of ADL or IADL limitations varied significantly over time. Prevalence of ADL varied significantly over time among non-Hispanic Black respondents $(P=0.049)(a)$, respondents with high school education or less $(P=0.003)(\mathrm{c})$, and respondents with income $\leq 250 \%$ FPL $(P=0.046)(\mathrm{e})$, but did not vary significantly among other subgroups. Prevalence of IADL varied significantly over time among non-Hispanic Black respondents $(P=0.003)(b)$, respondents with high school education or less $(P<0.001)(d)$, and respondents with income $\leq 250 \%$ FPL $(P=0.013)$ and respondents with income $>250 \%$ FPL $(P=0.028)(e)$, but did not vary significantly among other subgroups. In logistic regression with a group-by-time interaction term, there were no significant interactions between time and sociodemographic characteristics, meaning disparities between subgroups remained stable over time. b Instrumental Activities of Daily Living Limitation Prevalence,

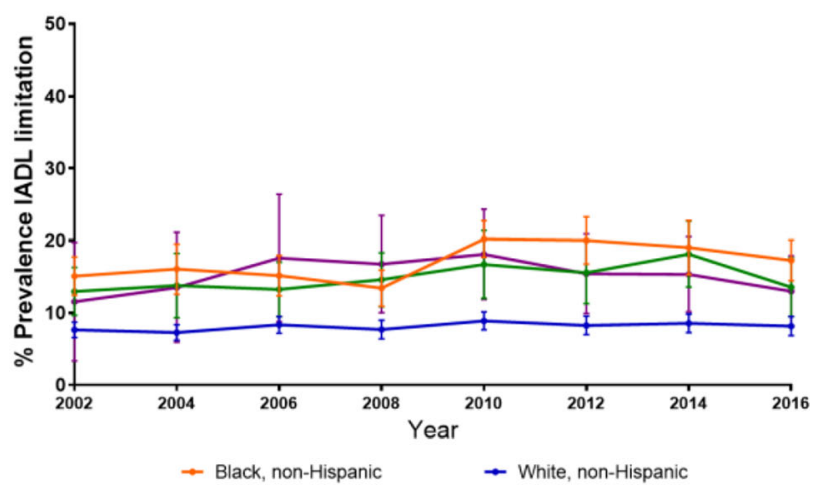

d Instrumental Activities of Daily Living Limitation Prevalence,

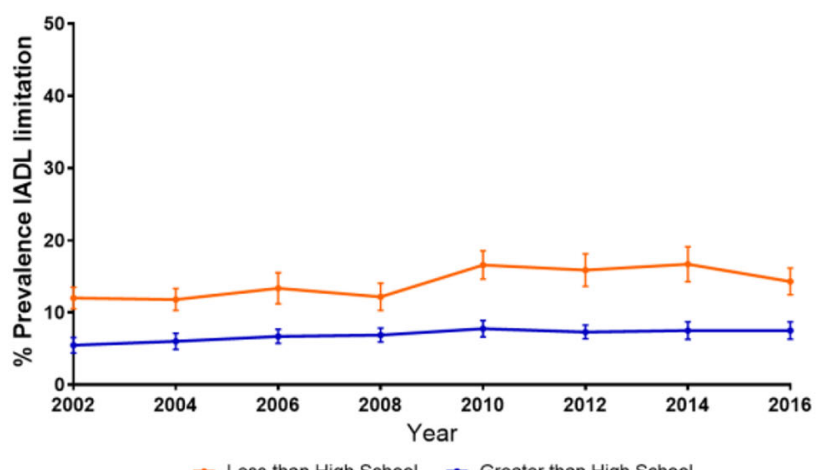

f Instrumental Activities of Daily Living Limitation Prevalence,

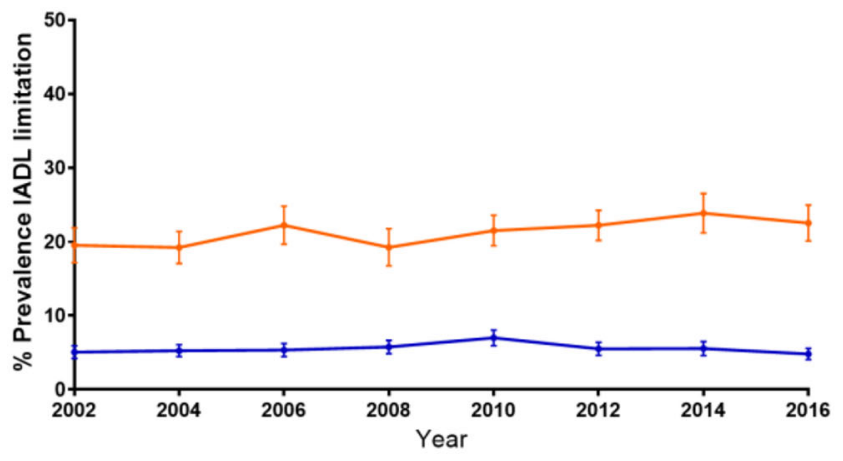

$\rightarrow \leq 250 \% \mathrm{FPL} \quad \rightarrow>250 \% \mathrm{FPL}$ 
Acknowledgments: We thank and acknowledge Jamie Luster, MPH, for assistance with drafting the table and figure. She was not compensated for this contribution beyond her usual salary. We also thank Vicki A. Freedman, PhD, for thoughtful comments on earlier drafts of this manuscript.

Renuka Tipirneni, $M D, M^{1,2}$

Monita Karmakar, $\mathrm{PhD}, \mathrm{MS}^{1}$

Donovan T. Maust, $M D, M^{2,3,4}$

${ }^{1}$ Division of General Medicine, Department of Internal Medicine, University of Michigan,

Ann Arbor, MI, USA

${ }^{2}$ Institute for Healthcare Policy and Innovation, University of Michigan,

Ann Arbor, MI, USA

${ }^{3}$ Department of Psychiatry, University of Michigan, Ann Arbor, MI, USA

${ }^{4}$ Center for Clinical Management Research, Veterans Affairs Ann Arbor Healthcare System,

Ann Arbor, MI, USA

Corresponding Author: Renuka Tipirneni, MD, MSc; Division of General Medicine, Department of Internal Medicine, University of Michigan, Ann Arbor, MI, USA (e-mail: rtipirne@med.umich.edu).

Funding Support was provided to Drs. Tipirneni and Karmakar from the National Institute on Aging (1K08AG056591).

\section{Compliance with Ethical Standards:}

The University of Michigan institutional review board approved the study.

Conflict of Interest: The authors declare that they do not have a conflict of interest.

\section{REFERENCES}

1. Woolf SH, Schoomaker $\mathbf{H}$. Life expectancy and mortality rates in the United States, 1959-2017. JAMA. 2019;322(20):1996-2016.

2. Chetty $\mathbf{R}$, Stepner $\mathbf{M}$, Abraham $\mathbf{S}$, et al. The association between income and life expectancy in the United States, 2001-2014. JAMA. 2016;315(16): 1750-66.

3. Davis MA, Guo C, Sol K, Langa KM, Nallamothu BK. Trends and disparities in the number of self-reported healthy older adults in the United States, 2000 to 2014. JAMA Intern Med 2017;177(11):1683-4.

4. Zajacova A, Montez JK. Explaining the increasing disability prevalence among mid-life US adults, 2002 to 2016. Soc Sci Med 2018;211:1-8.

5. Brown RT, Diaz-Ramirez LG, Boscardin WJ, Lee SJ, Steinman MA. Functional impairment and decline in middle age: A cohort study. Ann Intern Med 2017;167(11):761-8.

6. Freedman VA, Martin LG, Schoeni RF. Recent trends in disability and functioning among older adults in the United States: A systematic review. JAMA. 2002;288(24):3137-46.

Publisher's Note Springer Nature remains neutral with regard to jurisdictional claims in published maps and institutional affiliations. 